www.jmscr.igmpublication.org

Impact Factor 5.84

Index Copernicus Value: 83.27

ISSN (e)-2347-176x ISSN (p) 2455-0450

crossref DOI: _https://dx.doi.org/10.18535/jmscr/v5i4.135

Journal Of Medical Science And Clinical Research

IGM Publication

An official Publication of IGM Publication

\title{
The Prevalence and Clinico-Epidemiological Profile of Celiac Disease in Anaemic Children Admitted At a Tertiary Care Hospital of North West Rajasthan (India)
}

Authors

Dr Vikash Katewa ${ }^{1}$, Dr Vijendra Kumar Garg ${ }^{2}$, Dr Suman Katewa ${ }^{3}$, Dr Manoj Kumar ${ }^{4}$, Dr Ravi Kumar $K^{5}$, Dr Kapil Choradiya ${ }^{6}$

${ }^{1}$ Assistant Professor, Department of Pediatrics, Dr.S.N. Medical College Jodhpur (Rajasthan)

${ }^{2}$ Assistant Professor, Department of Pediatrics, SMS Medical College Jaipur (Rajasthan)

${ }^{3}$ Senior Resident, Department of Obstetrics \& Gynaecology, Dr.S.N. Medical College Jodhpur (Rajasthan)

${ }^{4,5,6}$ Resident, Department of Pediatrics, Dr.S.N. Medical College Jodhpur (Rajasthan)

Corresponding Author

Dr Vikash Katewa

Assistant Professor, Department of Pediatrics, Dr.S.N. Medical College Jodhpur (Rajasthan)

Email:drvikaskatewa@gmail.com

\begin{abstract}
Background: Celiac disease is an immune-mediated systemic disorder elicited by gluten sensitivity in genetically susceptible people. Anaemia is a common extra intestinal manifestation of celiac disease.

Objectives: To determine the prevalence of Celiac disease in anaemic children and to explore their clinico- epidemiological profile.

Methods: A total of 1080 children having anaemia were enrolled for the study over a period of one and half years. All the enrolled children were subjected to hemogram, anti tissue transglutaminase (IgA $t \mathrm{Tg}$ ) antibody test. Children having positive serology for celiac disease underwent duodenal biopsy. The diagnosis of celiac disease was established on the basis of the revised European Society of Paediatric Gastroenterologists and Nutritionists (ESPGAN) criteria.

Results: Out of 1080 enrolled anaemic children, 130 were diagnosed as Celiac disease (12.04\%). Mean age at the time of diagnosis was $6.96 \pm 3.69$ years. Microcytic hypochromic was the commonest type of anemia (76.93\%) followed by dimorphic. Prevalence of Celiac disease was significantly higher in stunted children $(22.86 \%)$ as compared to children with normal height (6.85\%). Marsh stage IIIc was the commonest (61.54\%) histopathological finding. The mean haemoglobin level was significantly lower in children with celiac disease when compared to those without celiac disease.

Conclusion: There is high prevalence of Celiac disease among anemic children emphasizing the need for screening of Celiac disease in anemic children.

Keywords: Celiac disease (CD), Anemia, Anti-tissue transglutaminase antibody.
\end{abstract}

\section{Introduction}

Celiac disease (CD), also known as glutensensitive enteropathy or Celiac sprue, is defined as a permanent intolerance to ingested gluten (the storage protein components of wheat, barley and rye). The intolerance to gluten results in immune- 
mediated damage to the mucosa of the small intestine characteristically inducing villous atrophy and crypt hyperplasia that resolve with the removal of gluten from the diet ${ }^{[1]}$.

Studies have shown that the Celiac disease is occurring in 1 out of every 100 to 300 individuals in the general population worldwide ${ }^{[2]},{ }^{[3]}$. Celiac disease, once thought to be rare, is now known to affect as much as $1 \%$ of the population and is not an uncommon condition in northern India particularly Punjab and Rajasthan ${ }^{[4]-[6]}$.On the basis of clinical presentation $\mathrm{CD}$ is classified in two subtypes. Classic subtype presents with chronic diarrhoea, failure to thrive, abdominal distension, and weight loss while in atypical form the disease may present insidiously, for example with anemia, osteoporosis, cryptogenic hyper transaminasemia, or neurological symptoms. CD can be clinically silent, often detected by serologic screening of those subjects at risk, with villous atrophy in the intestine ${ }^{[7]}$.

Anemia can be the sole manifestation of the disease without overt malabsorption which can occur in any age, sex or ethnic group ${ }^{[8]-[10]}$. The anemia of CD is usually due to malabsorption of micronutrients such as iron, folic acid, and vitamin B12 ${ }^{[11]}$.

Anemia in celiac disease is usually hypoproliferative reflecting impaired absorption of nutrient like iron and various vitamins. Most common type of anemia in celiac disease is iron deficiency anemia. Iron deficiency is usually attributed to enteropathy characterized

by mucosal damage of the small intestine that results in impaired absorption of but there may also be occult blood loss in GIT $^{[12], ~[13]}$. The prevalence of celiac disease has been observed between $0 \%$ to $8.7 \%$ in patients referred for assessment of iron deficiency anemia ${ }^{[14],[15]}$.The current study was conducted with the objective to determine the prevalence of celiac disease in anemic children and to explore their clinicoepidemiological profile in north west region of Rajasthan.

\section{Materials and Methods}

This study was conducted at Department of Paediatrics in collaboration with Department of Gastroenterology, Department of Microbiology and Department of Pathology, Sardar Patel Medical College Bikaner (Rajasthan) over a period of one $\&$ half years. After approval from institutional ethical committee, total 1080 children aged between 1-15 years who were having anemia, as per WHO definition of anemia, were enrolled for this study ${ }^{[16]}$. Patients with obvious blood loss, such as those with a history of melena, hematochezia, hemoptysis, recurrent epistaxis, hematuria, trauma, serious respiratory or cardiac disorders, hypermenorrhea (periods $\geq 7$ days), menometrorrhagia, gastric surgery, known chronic diseases and hematologic diseases like thalassemia, having diagnosis of malaria were excluded from the study

Detailed clinical profile, epidemiological data including age, sex, socioeconomic status were recorded. Hematological data eg. haemoglobin, hematocrit, $\mathrm{MCV}, \mathrm{MCH}, \mathrm{MCHC}$ and $\mathrm{PBF}$ details were recorded. Anthropometric measurement eg. height \& weight were measured and weight for height, height for age and weight for height were plotted in growth charts and graded according to WHO classification for under nutrition.

All children included in the study group were screened for celiac disease by serological test IgA-anti tissue transglutaminase (IgA tTG antibodies) by Enzyme Linked Immunosorbent assay (ELISA ) method. IgA tTG value greater 50 $\mathrm{IU} / \mathrm{ml}$ was considered positive.

Upper gastrointestinal endoscopy for small bowel biopsy from the second part of the duodenum was performed in children with positive screening whose parents provided written consent and at least four biopsy samples were obtained for each subject. Histopathological findings were expressed according to the Marsh classification ${ }^{[17]}$. The diagnosis of celiac disease was established on the basis of the revised European Society of Paediatric Gastroenterologists and Nutritionists (ESPGAN) criteria ${ }^{[18]}$. 


\section{Results}

Data were recorded and statistical analysis was performed using appropriate statistical method. Out of 1080 children 580 were male and 500 were female. The male to female ratio was 1.16:1. Out of 1080 children $510(47.22 \%)$ were below 5 years of age, 420 (38.89\%) were between 5-10 years and $150(13.89 \%)$ were between $10-15$ years of age. Total 160 children had positive serology for CD by IgA tTG antibodies test. Parents of 15 children refused for endoscopy and remaining 145 children underwent upper gastrointestinal endoscopy and biopsy samples were taken from second part of duodenum. Histopathological finding were consistent with celiac disease in 130 of them. Duodenal biopsy in 80 (61.54\%), $20(15.38 \%), 20(15.38 \%)$ and $10(7.69 \%)$ children was suggestive of modified Marsh stage IIIc, IIIb, II and IIIa respectively. The prevalence of biopsy proven celiac disease was $12.04 \%$ while $1.38 \%$ children were labeled as latent celiac as they were positive for celiac serology but their histology was normal.

Out of these 130 confirmed celiac patients, 70 $(53.84 \%)$ were male while $60(46.16 \%)$ were female. Mean age of celiac positive children was $6.96 \pm 3.69$ years (range $1-15$ years). Celiac disease was more prevalent in 5-10 years age group (16.67\%; 70 in 420), followed by $<5$ year age group $(9.80 \% ; 50$ in 510$)$ and $10-15$ year age group $(6.67 \% ; 10$ in 150). Main clinical features observed in confirmed celiac children were diarrhea (69.23\%), abdominal distension $(61.54 \%)$, anorexia (53.84\%), sign of vitamin deficiency (46.15\%), pain abdomen (38.46\%), edema $(8.46 \%)$, skin hyper pigmentation $(9.77 \%)$, vomiting (13.07\%) and constipation (15.38\%) while $23.07 \%$ children were having no gastrointestinal symptomtology (Table 1). Mean hemoglobin in children with $\mathrm{CD}$ was $6.96 \pm 1.78$ gm\% while mean values of $\mathrm{MCV}, \mathrm{MCH}, \mathrm{MCHC}$ were $\quad 67.13 \pm 9.77(\mathrm{fl}), \quad 20.86 \pm 4.73(\mathrm{pg}) \quad$ and $28.16 \pm 2.84(\mathrm{gm} \%)$ respectively. Most common type of anemia was microcytic hypochromic (76.93\%) while normocytic normochromic anemia was present in $15.38 \%$ children, remaining $7.69 \%$ celiac children had dimorphic anemia. Celiac disease was more prevalent in the stunted (height for age $<3^{\text {rd }}$ percentile) anemic children $(22.86 \%$; 80 in 350) as compared to anemic children with height for age $>3^{\text {rd }}$ percentile $(6.85 \% ; 50$ in 730$)$ and this difference was statistically highly significant ( $\mathrm{p}$-value $=0.016$ ). Maximum number of diagnosed celiac children belonged to lower middle and lower socioeconomic class (40; $30.76 \%$ each) followed by upper middle and upper lower $(20 ; 15.38 \%$ each) while 10 (7.70\%) children belonged to upper socio-economic class. In table 2 the mean $\mathrm{Hb}, \mathrm{HCT}, \mathrm{MCV}, \mathrm{MCH}$ in anemic children are compared with the levels in anemic children without $\mathrm{CD}$. The mean $\mathrm{Hb}$ level was significantly lower in anemic children with $\mathrm{CD}$ than in those without $\mathrm{CD}(6.96 \pm 1.78$ vs. $8.24 \pm 1.65$, $p$ value $<0.05$ ) and this difference was statistically significant. Mean $\mathrm{Hb}$ value in celiac children with different Marsh stage was $7.12 \pm 1.3$ gm $\%, 7.82 \pm 1.02 \mathrm{gm} \%, 6.66 \pm 2.1 \mathrm{gm} \%$ \& $6.5 \pm 1.07$ gm\% in stage II, stage IIIa, stage IIIb \& stage IIIc respectively. There was no statistically significant difference in mean $\mathrm{Hb}$ value when it was compared based on Marsh staging.

Table 1: Characteristics of anemic children with $\mathrm{CD}(\mathrm{n}=130)$

\begin{tabular}{|c|c|c|}
\hline \multicolumn{2}{|l|}{ Characteristic } & Numbers( $\%)$ \\
\hline \multirow[t]{2}{*}{ Gender } & Male & $70(53.84 \%)$ \\
\hline & Female & $60(46.16 \%)$ \\
\hline \multirow{5}{*}{$\begin{array}{l}\text { Socioeconomic } \\
\text { status }\end{array}$} & Upper (I) & $10(7.70 \%)$ \\
\hline & Upper middle (II) & $20(15.38 \%)$ \\
\hline & Lower middle (III) & $40(30.76 \%)$ \\
\hline & Upper Lower (IV) & $20(15.38 \%)$ \\
\hline & Lower $(\mathrm{V})$ & $40(30.76 \%)$ \\
\hline \multirow{7}{*}{$\begin{array}{l}\text { Clinical } \\
\text { manifestation }\end{array}$} & Diarrhoea & $90(69.23 \%)$ \\
\hline & Abdominal distension & $80(61.54 \%)$ \\
\hline & Pain abdomen & $50(38.46 \%)$ \\
\hline & Constipation & $20(15.38 \%)$ \\
\hline & Sign of Vitamin deficiency & $60(46.15 \%)$ \\
\hline & Anorexia & $70(53.84 \%)$ \\
\hline & $\begin{array}{l}\text { No gastrointestinal sign\& } \\
\text { symptom }\end{array}$ & $30(23.07 \%)$ \\
\hline \multirow[t]{2}{*}{ Height for age } & $<3^{\text {rd }}$ percentile & $80(61.53 \%)$ \\
\hline & $>3^{\text {rd }}$ percentile & $50(38.47 \%)$ \\
\hline \multirow[t]{2}{*}{ Weight for age } & $<3^{\text {rd }}$ percentile & $90(69.23 \%)$ \\
\hline & $>3^{\text {rd }}$ percentile & $40(31.77 \%)$ \\
\hline \multirow{2}{*}{$\begin{array}{ll}\text { Type } & \text { of } \\
\text { anemia } & \end{array}$} & Microcytic Hypochromic & $100(76.93 \%)$ \\
\hline & Normocytic Normochromic & $20(15.38 \%)$ \\
\hline
\end{tabular}




\begin{tabular}{|l|l|l|}
\hline $\begin{array}{l}\text { (Based on PBF } \\
\text { picture) }\end{array}$ & Dimorphic & $10(7.69 \%)$ \\
\hline Marsh Staging & Marsh I & 0 \\
\cline { 2 - 3 } & Marsh II & $20(15.38 \%)$ \\
\cline { 2 - 3 } & Marsh IIIa & $10(7.69)$ \\
\cline { 2 - 3 } & Marsh IIIb & $20(15.38 \%)$ \\
\cline { 2 - 3 } & Marsh IIIc & $80(61.54 \%)$ \\
\hline
\end{tabular}

Table 2: Comparison of haematological parameters in anemic children with \& without CD

\begin{tabular}{|l|c|c|c|}
\hline Parameter & CD patients & Non CD patients & P value \\
\hline $\mathrm{Hb}$ & $6.96 \pm 1.78$ & $8.24 \pm 1.65$ & $<0.05$ \\
\hline $\mathrm{HCT}$ & $20.5 \pm 4.3$ & $25.14 \pm 3.7$ & $<0.05$ \\
\hline $\mathrm{MCV}$ & $67.13 \pm 9.77$ & $72.87 \pm 2.4$ & $>0.05$ \\
\hline $\mathrm{MCH}$ & $20.86 \pm 4.73$ & $24.12 \pm 1.6$ & $>0.05$ \\
\hline
\end{tabular}

\section{Discussion}

Celiac disease is an autoimmune enteropathy attributable to gluten in the diet. The spectrum of the disease ranges from overt malabsorption to clinically silent condition. Anemia may be the only presentation even in the absence of gastrointestinal symptoms. Celiac disease is often diagnosed in patient affected by anemia and in particular it is subclinical form of celiac disease that turn out to be a frequent cause of anemia. Clinicians may fail to consider celiac disease as a cause of anemia in children who do not have associated gastrointestinal symptoms. In the current study a large number (23.07\%) of anemic children with celiac disease did not report any gastrointestinal symptoms in accordance with earlier reports showing that most cases of $\mathrm{CD}$ in iron deficiency anemia appear to be atypical or silent, determined only by a screening tests ${ }^{[19] .}$

In a study by Unsworth et al prevalence of celiac disease in anemic children was reported $6.6 \%{ }^{[20]}$.Similarly in another study by Howard et al ,the prevalence of Celiac disease in anemic patient was found $10.9 \%$ while Annibale et al reported $13.7 \%$ prevalence of

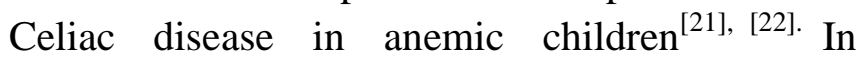
another study by Grisolano et al, 103 anemic patients were screened by duodenal biopsy and $8.7 \%$ were found positive on biopsy ${ }^{[15]}$. Recently, Zamani et al found the celiac disease prevalence as $14.6 \%$ in patient with IDA of obscure origin ${ }^{[2]}$. Prevalence of celiac disease in our study was slightly higher (12.04\%) as compared to previous studies indicating higher prevalence of celiac disease in anemic children in North West India.

In the current study mean age at diagnosis was $6.96 \pm 3.69$ years. A study done by Patwari A. $K$. et al had shown that the mean age at the time of presentation was $6.67 \pm 2.37$ years ${ }^{[23]}$. In a study by Poddar $U$ et al mean age of 50 children with celiac disease was $6.3 \pm 2.6$ years $^{[24]}$. Result of our study in term of mean age of presentation are comparable with above mentioned studies.

We also studied the prevalence of celiac disease in relation to socioeconomic status. Table 1 shows that in our study celiac disease was more prevalent in upper lower and lower socioeconomic class (18.18\% each) as compared to upper (9.09\%), upper middle $(7.7 \%)$ and lower middle $(10.5 \%)$. In a population study in adults Lewis $\mathrm{N} R$ et al had concluded that the incidence rate of celiac disease was twice as high in people from affluent areas compared with that in people living in poorer areas ${ }^{[25]}$. Results of our study was different from above study, this can be explained by the fact that anemia is more prevalent in lower socioeconomic class and in our study group anemic children from upper socioeconomic class were less in number or it be due to changing pattern of disease. Beside this the prevalence of middle and lower socioeconomic class in general population is higher in developing country like India and especially in state like Rajasthan.

Prevalence was significantly higher in stunted anemic children (22.86\%) as compared to normal children $(6.85 \%)$, this emphasise the need of early screening for celiac disease in stunted anemic children for cause of anemia and growth retardation.

In our study we also classified patients according to the type of anemia on the basis of peripheral blood film finding. Microcytic hypochromic anemia was commonest (76.92\%), followed by normocytic normochromic (15.38\%) and least 
common finding was dimorphic anemia (7.69\%). Patwari AK et al also observed microcytic hypochromic anemia in $80 \%$ and dimorphic anemia in only in $20 \%$ cases $^{[23]}$. Results of our study in term of type of anemia are comparable with above mentioned study.

Limitation of the current study is that for screening only Ig AtTG levels were done. In the current study no test for antiendomysial antibody and for HLA-DQ2 and HLA-DQ8 were performed to strongly exclude the diagnosis of celiac disease as in children with Ig A deficiency, the titres of IgAtTG may be falsely low.

\section{Conclusion}

As the prevalence of $\mathrm{CD}$ is high in the community, it should therefore be considered as a potential etiological factor in any patient presenting with anemia. Pediatricians must be aware that only a portion of $\mathrm{CD}$ cases are clinically overt, atypical forms are more common in children than previously considered and the disease may be diagnosed after a variable time of gluten exposure even after exposure of years. So to conclude emphasis should be made to screen for celiac disease sc by antitTGA as a routine in children with anemia.

\section{References}

1. RJ, Kelly CP. Celiac sprue - current concepts. NEngl J Med 2002; 346:180-188.

2. Zamani F, Mohamadnejad M, Shakeri R, et al. Gluten sensitiveenteropathy in patients with iron deficiency anemia of unknown origin. World J Gastroenterol 2008; 14:7381-5.

3. Ertekin V, Selimoglu MA, Kardas F, Aktafl E. Prevalence of celiac disease in Turkish children. J Clin Gastroenterol 2005; 39:689-91

4. Makharia G K, Verma A K. Amarchand $\mathrm{R}$,et alPrevalence of celiac disease in the northern part of India: a community based study.J Gastroenterol Hepatol. .2011 May;26(5):894-900.
5. Bhattacharya M, Dubey AP, Mathur NB. Prevalence of Celiacdisease in North Indian Children. Indian Pediatr 2009 May; 46(5): 4157

6. Sood A, Midha V, Sood N, Avasthi G,Sehgal A. Prevalence of celiac disease among school children in Punjab, North India. J Gastroentero Hepatol.2006;21 (10):1662,1625.2006.

7. Baccini F, Spiriti MA, Vannella L et al. Unawareness of gastrointestinal symptomatology in adult coeliac patients with unexplained iron-deficiency anaemia presentation. Aliment Pharmacol Ther 2006; 23:915-21

8. G Bottaro, F Cataldo, N Rotolo, et al. The clinical pattern of subclinical/silent celiac disease: an analysis on 1026 consecutive cases. Am J Gastroenterol 1999;94:691-6.

9. RJ Mody, PI Brown, DS Wechsler. Refractory iron deficiency anemia as the primary clinical manifestation of celiac disease. J PediatrHematolOncol 2003;25:169-72.

10. M Economou, S Karyda, N Gombakis, et al. Subclinical celiac disease in children: refractory iron deficiency as the sole presentation. J PediatrHematolOncol 2004;26:153-4. author reply 154.

11. TR Halfdanarson, MR Litzow, JA Murray. Hematologic manifestations of celiac disease. Blood 2007;109:412-21

12. de Vizia B, Poggi V, Conenna R, Fiorillo A, Scippa L. Iron absorption and iron deficiency in infants and children with gastrointestinal diseases. $\mathrm{J}$ Pediatr Gastroenterol Nutr. 1992;14:21-26

13. Kosnai I, Kuitunen P, Siimes MA. Iron deficiency in children with coeliac disease on treatment with gluten-free diet: role of intestinal blood loss. Arch.Dis Child. 1979;54:375-378

14. Bini EJ, Micale PL, Weinshel EH. Evaluation of the gastrointestinal tract in premenopausal women with iron 
deficiency anemia. Am J Med. 1998; 105:281-286.

15. Grisolano SW, Oxentenko AS, Murray JA, Burgart LJ, Dierkhising RA, Alexander JA. The usefulness of routine small bowel biopsies in evaluation of iron deficiency anemia. J Clin Gastroenterol. 2004; 38:756-760

16. Iron deficiency anemia : assessment , prevention \& control .A guide for programme manager, Geneva . WHO ,2001 (WHO/NHD/01.3)

17. Marsh MN. Gluten, Major histocampatibility complex and the small intestine. A molecular and immunobiologic approach to the spectrum of gluten insensitivity. Gastroenterology 1992; 102:330-354.

18. Working Group of Europian Society of Pediatric Gastroenterology and Nutrition. Revised criteria for diagnosis of celiac disease .Arch Dis Child 1990;58:409-13.

19. Ehsani-Ardakani MJ, Rostami Nejad M, Villanacci V, Volta U, Manenti S, Caio G, et al. Gastrointestinal and Nongastrointestinal Presentation in Patients with Celiac Disease. Arch Iran Med. 2013;16(2):78-82.

20. Unsworth DJ, Lock RJ, Harvey RF. Improving the diagnosis of coeliac disease in anaemic women $\mathrm{Br} \mathrm{J}$ Haematol. 2000;111:898-901.

21. Howard MR, Turnbull AJ, Morley P, Hollier P, Webb R, Clarke A. A prospective study of the prevalence of undiagnosed coeliac disease in laboratory defined iron and folate deficiency. J Clin Pathol. 2002;55: 754-757

22. B Annibale, C Severi,A Chistolini,et al. Efficacy of gluten free diet alone on recovery from iron deficiency anemia in adult celiac patients. Am J Gastroenterol 2001;96:132-7 .

23. Patwari A.K, Anand V.K, Gaurav Kapur, Shashi Narayan. Clinical and Nutritional profile of children with Celiac disease. Indian pediatrics 2003;40:337-342.

24. Poddar U ,Thappa BR ,Nain CK ,et al. celiac disease in India : are they true cases of celiac disease ? J Pediatr Gastroenterol Nutr .2002 Oct ;35(4) :508-12.

25. Lewis NR, Logan RFA, Sanders DS, et al.PTH-091 Is the diagnosis of coeliac disease associated with socio-economic status? A population-based study Gut 2010;59:A160. 